\title{
THE HERITABILITY OF RELIGIOUSNESS: AN INTERNATIONAL TWIN STUDY
}

\section{Amy E. Steffes}

University of Wisconsin - Eau Claire Faculty Mentor: April Bleske-Rechek

\section{Background}

Emerging adulthood is a time of religious change for many

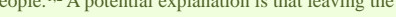

during emerging aluthood, allows for the expession occans own inherent dispositions.' ${ }^{1}$ Heritability is the proportion of variance in a measured trait that is due to genentic variation;

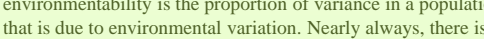
some degree of both environmentability and heritability

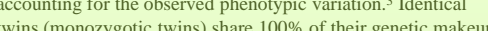
hare $50 \%$ of their genetic makeup. If monozygotic twins (MZ) resemble each other in religiousneess more than dizygotic twins $(\mathrm{DZ})$ resemble exh other, we can inter tart genetics are a factor in one's found to be Found to be heritable." Further, the heritability of religiousness found the heritability of religiounsness increased with age dealt
for with imited samples.". "hie puppose of the current stady is finding that religiousness is a heritable trait.

\section{Hypotheses}

religious involvement as children

than as adults.
In childhood,
t

In childhood, $\mathrm{MZ}$ twins will be about as similar as $\mathrm{DZ}$ twins in than $\mathrm{DZ}$ twins in religiousnes.

town) in adulthood, there will noar their home environment (hon .eng

\section{Method}

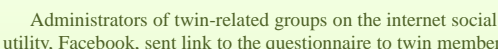
utility, Facebook, sent link to the questionnaire to twin members age 18 to 54 with a a average age of 224 A total of 102 . individuals responded about themselves and their $\mathrm{MZ}$ twin, and 156 individuals responded about themselves and their oppositesex or same-sex $\mathrm{DZ}$ twin. Of the $156 \mathrm{DZ}$ twins, 87 were same-

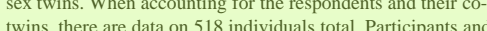
their twins reside mainly in the United States 3221 of 518 individuals), with 197 individuals residing in 20 other countries.
Althought this study contains data on individuals from many part of the world, the majority of participants who responded about denoming their own nand their co-twin's seligioious involvement and
affiliation during their childhood and adulthood.

Acknowledgements Dr. April Bleske-Rectiek was consulted regularly throughou the completion of this project. This research was sponsored, in
part, by University of Wisconsin-Eau Claire Differential Tuition.

\section{Results and Figures}

Scale Creation

The 5-item self-reported childhood and adulthood Religiousness Scales had internal consistencies (alpha) of 89 ( $N=$

$258)$ and $.93(N=258)$, respectively. The Internal Subscale consisted of three items, Importance of Faith in Daily Life,
Frequency of Prayer, and Freverency of Reading Religious Text it had an internal consistency in childhood and dulthoo of. $84(N=258)$ and 90 ( $(N=258)$, respectively. The External Subscale consisted of two items, Frequency of Attending Religious Services and Frequency of Discussing Religious
adulthood of $72(N=258)$ and $83(N=258)$ resegecios

Decrease in Religiousness

Supporting Hypothesis 1, religiousness in the current sample measured by the Religiousness Scale decreased fron

Supporting Hypothesis 1 , religiousness in the current sample measured by the Religiousness Scale decreased from
childhood to adulthood $(257)=7.3, p<$.001. Screres decreased from childhood to adulthood in boht the Internal $($ (257)

$3.82, p<.001$ and External Subscales $t(257)=10.6, p<.001$. Although all scales showed lower scores in adulthood tha
in childhood the effect size was

Thelindhood, the effect size was much higher for the External Scale $d=.66$ (a medium to large effect) than for the

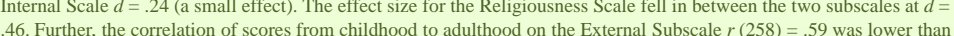

on the Ine

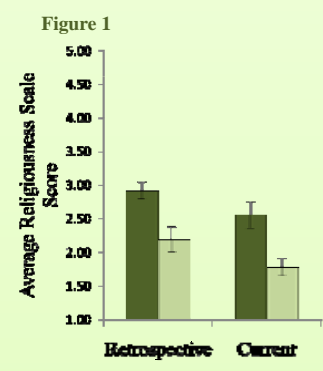

Heritability

Heritability was calculated as two times the difference betwern MZ and DZ conrelation coefficients. Heritability estimates $(h-1)$ for retrospective and current ratings on the Religiousness Scale
were. 02 and .26 , respectively. Supporting Hypothesis 2, MZ and $\mathrm{DZ}$ twins were about as similar in childhood but $\mathrm{MZ}$ twins were more similar than $\mathrm{DZ}$ twins in adulthood. Figure 2 shows the correlation coefficients for $\mathrm{MZ}$ and $\mathrm{DZ}$ twins in retrospective and current ratings. Error bars represent a 95\% Confidence Inte-

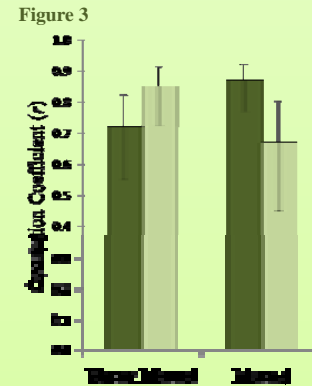
-Barr Inside the United States Bam Outside the

As shown in Figure 1, the decrease in religiousness was seen regardeless of country of origin. However, respondents Religiousness $S$ ache for estrospetive $(M=2.91, S D=0.94)$ nd current $(M=2.55, S D=1.23)$ ratings than did

spondents born outside the United States $(M=2.18, S D=$
$.93)$ and $(M=1.77, S D=1.77), \mathrm{t}(256)=6.12, \mathrm{p}<.001$

and $t(232.6)=6.07, p<.001$. Error bars represent a 95\%
Confidence Interval of the standard error of the mean.

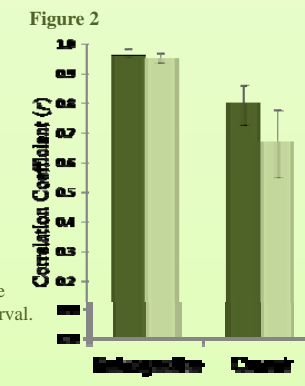

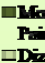

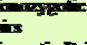
Although the heritability estimate ( $\left.h^{2}\right)$ for current ratings on the Religiousness Scale was .26 (as shown above in Figure 2), in adulthood, correlation coefficients of MZ
twins did not differ from that of $\mathrm{DZ}$ twins in the grom wins did not difter from that of DZ twins in the grot 3 . who never moved from home, as shown in Figure 3 .
the group who moved from home, the heritability estimate was much higher than when examining the groups together, hitting .40 for current ratings, supporting
Hypothesis 3 . Figure 3 depicts the difference between Hypothesis 3 . Figure 3 depicts the difference between
correlation coefficients for $\mathrm{MZ}$ twins and correlation correlation coefficients for $\mathrm{MZ}$ twins and correlation
coefficients for DZ twins when grouped by whether the respondent had moved at least 150 miles from home for th least four months. Error bars represent a 95\%
Discussion

The current study replicated and extended patterns found in

States are less religious in childhood and adulthood, the patterns of

me. The first pattern was the decrease

generally not more similar than $\mathrm{DZ}$ twins were in childhood, but $\mathrm{MZ}$

twin pairs with the responding twin never having lived more than 150

miles from home for at least four months, $\mathrm{MZ}$ twins were no more

similar than DZ twins in current responses on the religiousness scale.

However, when the responding twin had lived more than 150 miles
from home for four months or more, $\mathrm{MZ}$ twins were significantly

more similar than $\mathrm{DZ}$ twins. The active gene-environment correlation
could explain this phenomenon; the individuals who have moved from

their home environments have created their own environments to fit

with their genetic predispositions. Both $\mathrm{MZ}$ and $\mathrm{DZ}$ twins change, bu

because $\mathrm{DZ}$ twins only share half the amount of genes $\mathrm{MZ}$ twins

share, DZ twins become less similar to ea
their genetic predispositions are realized.

The External Subscale correlation from childhood to adulthood was significantly smaller than the Internal Subscale correlation from
childhood to adulthood. In childhood, Internal and External S Subseats

do not correlate or match as highly as in adulthood. This all points to

susceptible to change and the Interna

Subscale remaining more stable. ${ }^{5}$ External religiousness is easily

manipulated by the environment, parents making children to go church

more heritable over time, but internal religiousness remain more

Because it would have been impossible ensure both individuals in
twin pair participated, or to identify a participant's co-twin in the

dataset in the first place without compromising anonymity,

participants provided all ratings for themselves and their co-twins.

twins cold

zygosity and whether the rating was retrospective or current. ${ }^{5}$ While

these correlation coefficients are acceptable, they are not perfect. To
be conservative, whenever analyses were run for groups of individuals

(as opposed to groups of twins), only the respondents data were us

environment correlation) as a cause of phenotype similarity among

genetically similar individuals. However, much is still unknown abou

religiousness and its heritability in differing religions, heritability over

\section{References}

1. Koenig, L. B., McGue, M., \& lacono, W. G. (2008). Stability and change in

543.
Zinnbauer, B. J., \& Pargament, K. I. (1998). Spiritual conversinin: A studd of

religious change among college students. Journal for the Scientific Study
Religion, 37, 161-180.

akere, C. (2004). Behavioral genetics: An introduction to how genes and
environment interact through development to shape differences in mood,
persondiliy. and intelligence. Washington, DC: American Association for

personality, and intelligence. Washington, DC: American Association for the
Advancement of Sciences.

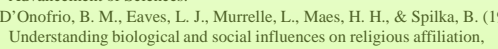

attitudes, and behaviors: $A$ S

Koenig, L. B., McGue, M., Krueger, R. F., \& Bouchard, T. J.J. J. (2005). Genetic
and environmental influences on religiousness: Findings for retrospective and 